\title{
Triptolide inhibits tumor growth by induction of cellular senescence
}

\author{
RUIDONG LI $^{1 *}$, XIAOFEI ZHANG ${ }^{1 *}$, XIAOYING TIAN ${ }^{2 *}$, CONGHUAN SHEN $^{1}$, QUANBAO ZHANG $^{1}$, \\ YIHONG ZHANG $^{2}$, ZHENGXIN WANG $^{1}$, FEIFEI WANG ${ }^{2}$ and YIFENG TAO ${ }^{1}$ \\ ${ }^{1}$ Department of General Surgery and Liver Transplant Center, Huashan Hospital, Fudan University, \\ Shanghai 200040; ${ }^{2}$ Bioscience Research Center, Shanghai 200120, P.R. China
}

Received May 31, 2016; Accepted October 26, 2016

DOI: $10.3892 /$ or.2016.5258

\begin{abstract}
Cellular senescence, an irreversible growth arrest of cells, is involved in protection against cancer. Triptolide (TPL) plays an important role in immunosuppressive, anti-fertility, anti-cystogenesis and anticancer activities. However, effect and mechanism of TPL on cellular senescence-associated antitumor is rarely reported. Herein HepG2 cells were used to explore the effect of TPL on tumor growth and cellular senescence. We showed that TPL inhibited tumor cell proliferation and growth in vitro and in vivo, accelerated cellular senescence and arrested cells at G0/G1 phase. We further demonstrated that TPL accelerated HepG2 cell senescence by regulating the AKT pathway. In addition, TPL could also enhance cellular senescence and inhibit tumor growth by negatively regulating human telomerase reverse transcriptase (hTERT) signaling pathway. These findings reveal a regulatory mechanism of TPL on cellular senescence, indicating that TPL promotes HepG2 cell senescence through AKT pathway and hTERT pathway simultaneously. Altogether, TPL-induced senescence can be regarded as a promising strategy for anticancer therapy and drug development.
\end{abstract}

Correspondence to: Dr Yifeng Tao, Department of General Surgery and Liver Transplant Center, Huashan Hospital, Fudan University, 12 Middle Wulumuqi Road, Shanghai 200040, P.R. China

E-mail: taoyifenghsh@126.com

Dr Feifei Wang, Bioscience Research Center, 588 Tianxiong Road, Shanghai 200120, P.R. China

E-mail: wangffbio@126.com

${ }^{*}$ Contributed equally

Abbreviations: Triptolide, TPL; Tripterygium wilfordii Hook F, TWHF; human telomerase reverse transcriptase, hTERT; Senescence-associated $\beta$-gal, SA- $\beta$-gal

Key words: cellular senescence, triptolide, HepG2 cell, AKT, human telomerase reverse transcriptase

\section{Introduction}

Liver cancer is one of the most common malignant tumors. According to the latest statistics, there were approximately 782,500 new liver cancer cases and 745,500 deaths that occurred worldwide during 2012 (1). Chemotherapy remains the primary therapeutic strategy for malignancies. However, recurrence, secondary cancer and normal tissue damage resulting from chemotherapy bring clinical problems for the cancer survivor. Therefore, it is urgent to develop the new and effective therapies for cancer.

As initially described by Hayflick and Moorhead, cellular senescence is an irreversible growth arrest of cells which occurs in proliferative cells (2). Cellular senescence can be induced by telomere shortening, DNA damage and oncogene activation (3). Previous studies demonstrated that cellular senescence is involved in protection against cancer and important for tumor inhibition (4-7). Given the tumor suppressive potential of senescence, it was suggested that pro-senescence therapy may be an effective way for anticancer therapy $(8,9)$.

Triptolide (TPL) is diterpenoid extracted from the plant, Tripterygium wilfordii Hook F (TWHF), which is a traditional Chinese medicinal herb (10). TPL has been shown to possess a unique and wide bioactivity, including immunosuppressive, anti-fertility and anti-cystogenesis activities (11). Recent studies have revealed that TPL is effective against a broad range of cancer types, including lung cancer $(12,13)$, breast cancer $(14,15)$, colon cancer (16), gastric cancer (15) and pancreatic cancer (17).

TPL displays antitumor effect by inhibiting proliferation, invasion, migration or inducing apoptosis. However, little is known about the mechanism of TPL on cellular senescenceassociated antitumor effect. We studied the effect of TPL on HepG2 cell senescence and tumor growth in vitro and in vivo, as well as the underlying molecular mechanisms, aiming at providing a promising strategy for cancer treatment and drug development.

\section{Materials and methods}

Cell culture, chemicals and transfection. HepG2 cells (Institute of Biochemistry and Cell Biology of the Chinese Academy of Sciences) were cultured in Dulbecco's modified Eagle's 
medium contained $10 \%$ (v/v) fetal bovine serum, $100 \mathrm{U} / \mathrm{ml}$ penicillin and $100 \mu \mathrm{g} / \mathrm{ml}$ streptomycin. Cells were treated with triptolide (TPL, Sigma-Aldrich) at the final concentration of 0-10 $\mathrm{nM}$ and/or 1.0 $\mu \mathrm{M}$ MK2206 (Selleck Chemicals) for the indicated period. Cells were cultured at $37^{\circ} \mathrm{C}$ in a humid atmosphere containing $5 \% \mathrm{CO}_{2}$. For overexpression of hTERT in HepG 2 cells, HepG 2 cells were transfected with the lentiviral constructs containing pre-hTERT.

Cell proliferation assay. HepG2 cells were seeded on 96-well plates at a density of $1 \times 10^{5}$ cell/well and cultured for $24 \mathrm{~h}$. Then the cells were treated with triptolide for the indicated period. Cell numbers were counted at the time point indicated in the relevant figure legend.

TUNEL assay. Apoptotic DNA fragmentation was examined using the One Step TUNEL Apoptosis Assay kit (C1089, Beyotime Institute of Biotechnology, Haimen, China) according to the manufacture's protocol. Briefly, cells were seeded into 24-well plates and treated with $2.5 \mathrm{nM}$ TPL for 1 day and 3 days, respectively. Then, cells were fixed in $4 \%$ paraformaldehyde for $30 \mathrm{~min}$ at $4^{\circ} \mathrm{C}$, permeabilized in $0.1 \%$ Triton $\mathrm{X}-100$ for $2 \mathrm{~min}$ on ice, followed by the TUNEL assay for $1 \mathrm{~h}$ at $37^{\circ} \mathrm{C}$. Cy3 (Cyanine 3)-labeled TUNEL-positive cells were imaged under a fluorescence microscope.

Annexin $V$ apoptosis assay. Cell apoptosis quantification was performed by Annexin V-FITC Apoptosis Detection kit (C1062, Beyotime Institute of Biotechnology). In brief, cells were treated with TPL and then washed with PBS. After the addition of $195 \mu \mathrm{l}$ binding buffer, $5 \mu \mathrm{l}$ FITC-labeled Annexin V was added and incubated for $10 \mathrm{~min}$ at room temperature. Then cells were incubated with $10 \mu \mathrm{l}$ propidium iodide (PI) for $10 \mathrm{~min}$ on ice in the dark and measured by FACS analysis.

Cell cycle analysis. HepG2 cells $\left(1.0 \times 10^{6}\right)$ were trypsinized and fixed in $75 \%$ ethanol at $-20^{\circ} \mathrm{C}$ overnight. After washing with PBS, the cells were resuspended in PBS buffer, supplemented with $100 \mu \mathrm{g} / \mathrm{ml}$ RNase A (Takara) at $4^{\circ} \mathrm{C}$ for $30 \mathrm{~min}$. Then cells were stained with PI $(100 \mu \mathrm{g} / \mathrm{ml})$ at $4^{\circ} \mathrm{C}$ for $30 \mathrm{~min}$. Finally the samples were analyzed by a flow cytometer (Becton Dickinson).

Senescence-associated $\beta$-gal staining. Senescence-associated $\beta$-gal (SA- $\beta$-gal) activity was carried out using SA- $\beta$-gal staining kit (Beyotime Biotechnology). Briefly, after removing medium, HepG2 cells were washed with PBS and fixed with $2 \%$ formaldehyde and $0.2 \%$ glutaraldehyde for $10 \mathrm{~min}$. Then, cells were washed with PBS and incubated with fresh SA- $\beta$-gal stain solution overnight at $37^{\circ} \mathrm{C}$ (without $\mathrm{CO}_{2}$ ). After staining, cells were photographed using a microscope (IX73, Olympus), and the percentage of senescence cell was determined via counting five random fields.

Real-time PCR. Total RNA was isolated using TRIzol kit (Invitrogen) according to the manufacturer's directions. Real-time PCR was performed using an ABI 7500 Real-Time PCR System (Applied Biosystems) with the One Step SYBR PrimeScript $^{\mathrm{TM}}$ Plus RT-PCR kit (Takara). The sequences of primers are listed in Table I.
Table I. Primers used in RT-PCR.

\begin{tabular}{ll}
\hline Primer name & \multicolumn{1}{c}{ Sequence } \\
\hline p53 & F: 5'-GAGGGATGTTTGGGAGATGTAA-3' \\
& R: 5'-CCCTGGTTAGTACGGTGAAGTG-3' \\
p21 & F: 5'-TGTCCGTCAGAACCCATGC-3' \\
& R: 5'-AAAGTCGAAGTTCCATCGCTC-3' \\
cyclin D1 & F: 5'-GAACAAACAGATCATCCGCAAAC-3' \\
& R: 5'-GCGGTAGTAGGACAGGAAGTTG-3' \\
hTERT & F: 5'-GCCTTCAAGAGCCACGTC-3' \\
& R: 5'-CCACGAACTGTCGCATGT-3' \\
3-actin & F: 5'-ACAGAGCCTCGCCTTTGCCGA-3' \\
& R: 5'-CACGATGGAGGGGAAGACG-3' \\
\hline
\end{tabular}

F, forward; R, reverse.

Western blotting. Western blots were performed based on the standard procedures. In brief, cells were lysed using ice-cold lysis buffer (Takara). The protein concentrations were measured using a BCA protein assay kit (Takara). For western blotting, protein extracts were subjected to $10 \%$ sodium dodecyl sulfate-polyacrylamide gel electrophoresis (SDS-PAGE) and transferred to polyvinylidene difluoride (PVDF) membranes. After incubation with blocking buffer (5\% fat-free milk), the membranes were incubated with primary antibodies (1:1000) overnight at $4^{\circ} \mathrm{C}$ and subsequently incubated with HRP-conjugated secondary antibodies for $1 \mathrm{~h}$ at room temperature. Finally, the membranes were exposed using ECL Chemiluminescent Substrate Reagent kit (Thermo Scientific). Mouse anti-human p53 monoclonal antibody (cat. no. ab1101), rabbit anti-human p21 polyclonal antibody (cat. no. ab7960), rabbit anti-human cyclin D1 monoclonal antibody (cat. no. ab16663), rabbit anti-human AKT (phospho S473) polyclonal antibody (cat. no. ab8932), rabbit antihuman AKT monoclonal antibody (cat. no. ab32505) and rabbit anti-human $\beta$-actin polyclonal antibody (cat. no. ab8227) were purchased from Abcam.

Telomerase activity assay. HepG2 cells were lysed with icecold lysis buffer (Takara). After centrifugation at 15,000 x g for $30 \mathrm{~min}$, the protein concentrations were measured using BCA protein assay kit (Takara). Telomerase activity assay was performed by using the telomeric repeat amplification protocol (TRAP) with the TeloTAGGG Telomerase PCR ELISA kit (Roche) according to the instructions of the manufacturer.

Establishment of a xenograft model in nude mice. BALB/C nude mice were purchased from Shanghai Bikai Lab Animal Co., Ltd. Xenograft was initiated by subcutaneous injection of $1 \times 10^{7}$ HepG2 cells in logarithmic phase into 6-8 weeks old nude mice. After 7 days, mice were treated with TPL $(25 \mathrm{mg} / \mathrm{kg})$ by intraperitoneal injection every day. There were 5 mice in each group. Weight of the mice and tumor growth were monitored every 3 days. The tumor volumes were measured by calipers. Tumor volumes were calculated according to the formula: 

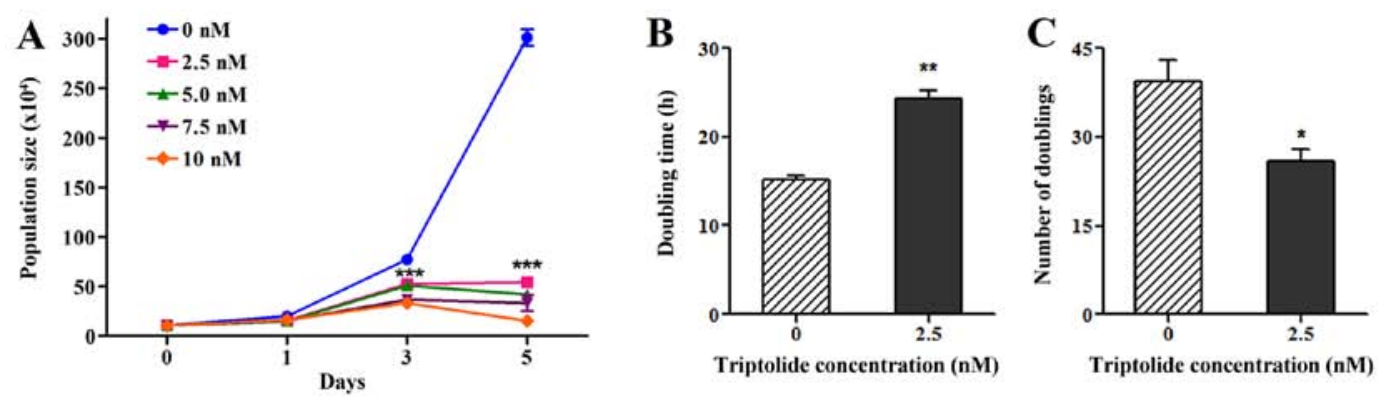

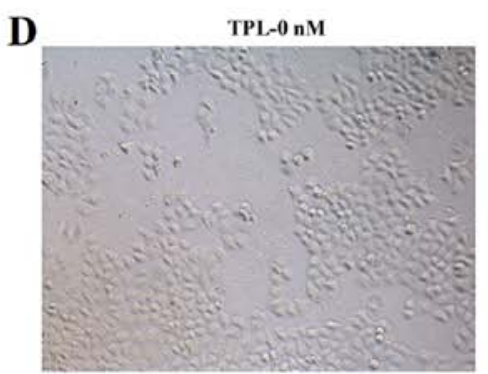

TPL-7.5 nM
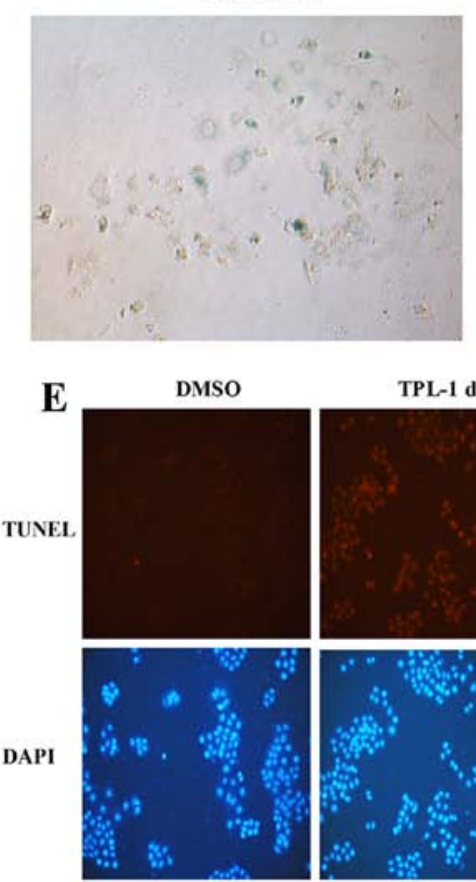

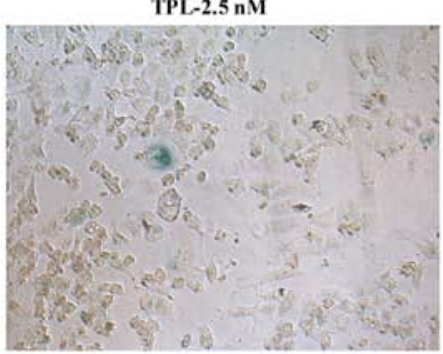

TPL-10 nM

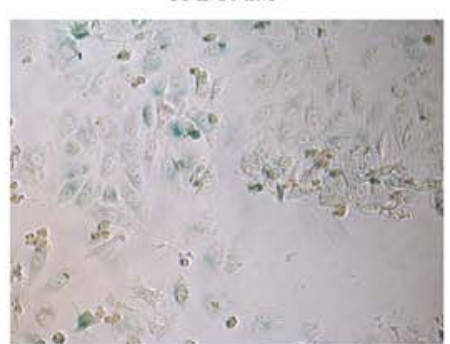

$\mathbf{F}$
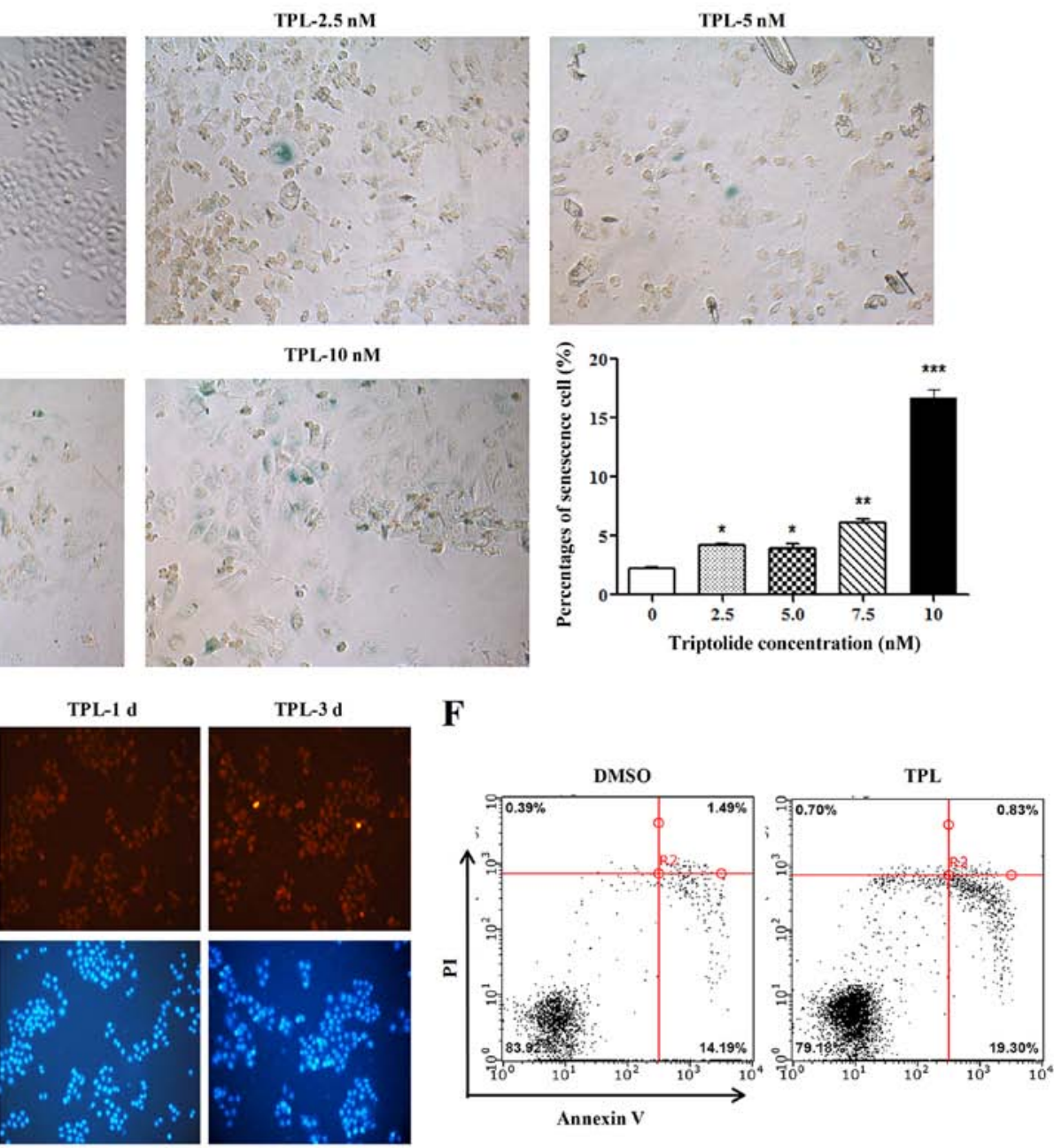

Figure 1. Effect of TPL on cell doubling time and cellular senescence. (A) The population size of untreated control HepG2 and treated cells with $0,2.5,5.0,7.5$ and $10 \mathrm{nM}$ TPL. (B) The doubling time (C) number of doubling of HepG2 cells with 0 and $2.5 \mathrm{nM}$ TPL treatment. (D) Senescence-associated $\beta$-gal staining of HepG2 cells treated with 0, 2.5, 5.0, 7.5 and $10 \mathrm{nM}$ TPL for 5 days (x200). (E) Cell apoptosis was determined by using TUNEL assay (x200). (F) Cell apoptosis was quantified by using flow cytometry. Data are presented as the mean $\pm \mathrm{SD}$ of three independent experiments. ${ }^{*} \mathrm{P}<0.05,{ }^{* * *} \mathrm{P}<0.01,{ }^{* * * *} \mathrm{P}<0.001$.

$\left(0.5 \times\right.$ length $\mathrm{x}$ width $\left.{ }^{2}\right)$. All experimental protocols using mice were approved by the Ethics Committee of Experimental Animals of Fudan University (Shanghai, China) and all experiments also conformed to the guidelines of the Chinese Association of Laboratory Animals. After 16 days, the mice were sacrificed when tumors reached a volume $>2000 \mathrm{~mm}^{3}$, and tumors were dissected and weighed.

Ki67 staining. After deparaffinized and dehydrated, sections were immersed in methanol with $0.3 \%$ (vol/vol) $\mathrm{H}_{2} \mathrm{O}_{2}$ for $30 \mathrm{~min}$ and then heated in citrate buffer $(10 \mathrm{mM}, \mathrm{pH} 6.0)$ at $120^{\circ} \mathrm{C}$ for $5 \mathrm{~min}$ in pressure cooker. Tumor tissue sections were incubated with primary antibody for Ki67 (polyclonal rabbit anti-human Ki67 antibody; 1:200, cat. no. ab15580; Abcam) overnight at $4^{\circ} \mathrm{C}$. Sections were incubated with biotinylated secondary antibody at room temperature for $1 \mathrm{~h}$ after washing with PBS buffer. Peroxidase activity was visualized with diaminobenzidine chromogen. Slides were mounted in Entellan (Merck KGaA) and observed under Olympus fluorescence microscopy (Olympus).

Statistical analysis. Data are shown as the mean \pm standard deviation (SD) using GraphPad Prism 5 software (GraphPad Software Inc.). Comparison between groups was performed using Student t-test. $\mathrm{P}<0.05$ was considered statistically significant. 

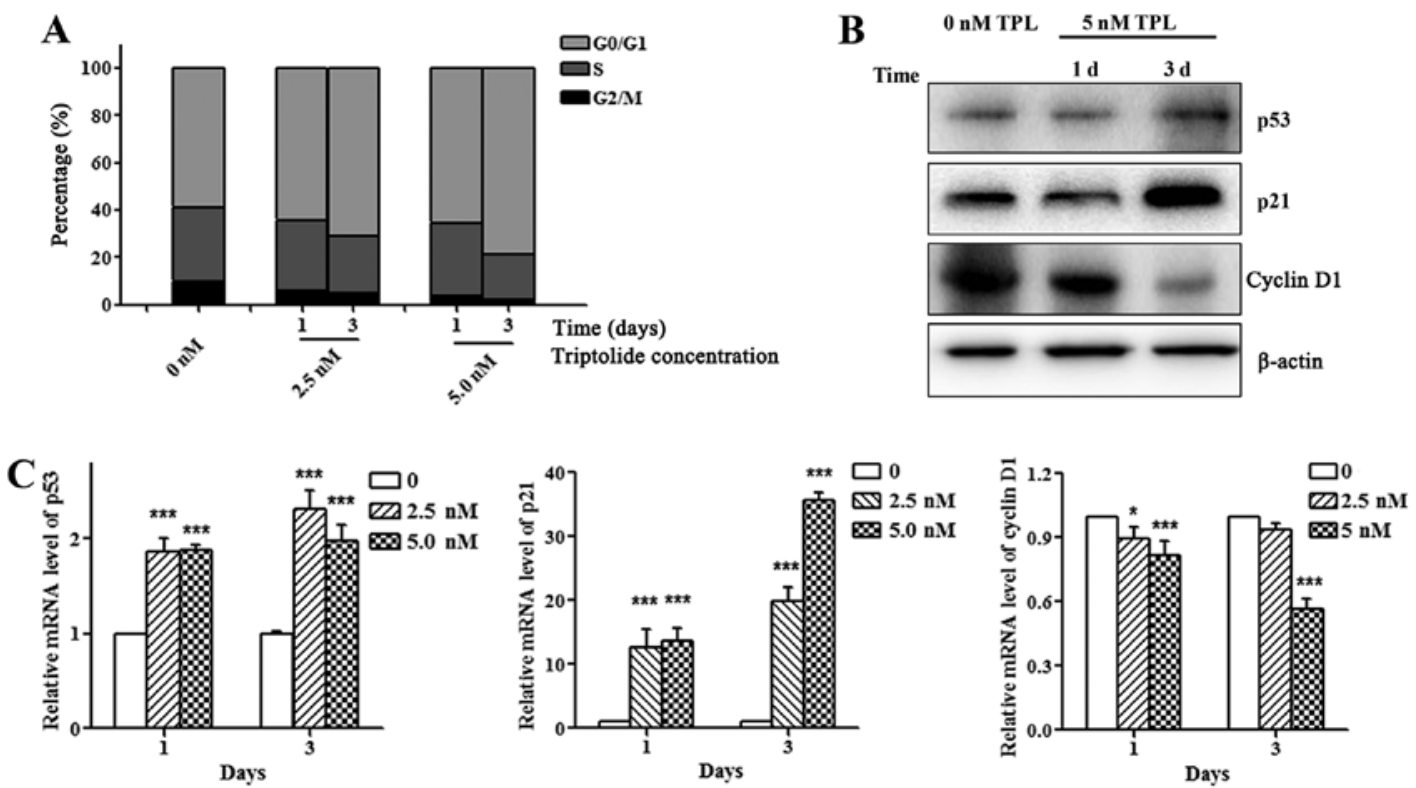

Figure 2. Effect of TPL on cell cycle distribution and related protein expression. (A) FACS analysis shows cell cycle distribution after TPL treatment. (B) Western blot analysis shows effect of TPL on p53, p21, cyclin D1 protein expression. (C) RT-PCR analysis shows effect of TPL on p53, p21, cyclin D1 mRNA expression. $\beta$-actin was used as internal control. Data are presented as the mean $\pm \mathrm{SD}$ of three independent experiments. ${ }^{*} \mathrm{P}<0.05,{ }^{* * *} \mathrm{P}<0.001$.

\section{Results}

TPL inhibits HepG2 cell proliferation and accelerates cellular senescence and apoptosis. Compared with control cells, treatment of HepG2 cells with 2.5, 5.0, 7.5 and $10 \mathrm{nM}$ TPL reduced the population size (Fig. 1A). Continuous culturing of HepG2 cells in a concentration of $2.5 \mathrm{nM}$ TPL, the doubling time of the cells increased significantly (Fig. 1B) while the number of doublings decreased (Fig. 1C) compared to the untreated controls. To further determine the effect of TPL on cellular senescence, the HepG2 cells were treated with 0. 2.5, 5.0, 7.5 and $10 \mathrm{nM}$ TPL, respectively. As shown in Fig. 1D, TPL accelerated cellular senescence in a dose-dependent manner. To test the effect of TPL on cell apoptosis, TUNEL assay and flow cytometry were performed to analyze level of apoptosis. Compared with control (DMSO) group, apoptosis of cells in TPL treatment groups were elevated (Fig. 1E and F).

TPL affects cell cycle distribution and related protein expression. To determine the effect of TPL on cell cycle, HepG2 cells were treated with $0,2.5,5.0 \mathrm{nM}$ TPL for 1 , or 3 days. Compared with control group, HepG2 cells treated with TPL had an increased percentage of cells at G0/G1 phase and decreased percentage of cells at G2/M phase (Fig. 2A). The p53/p21 signaling pathway is the key regulatory pathway of the cell cycle. As shown in Fig. 2B, treatment of HepG2 cells with TPL significantly increased the expression levels of p53 and p21 and decreased the cyclin D1 expression (Fig. 2B and C), suggesting that TPL arrests cells at G0/G1 phase by regulating the $\mathrm{p} 53 / \mathrm{p} 21$ pathway.

TPL enhances cellular senescence by activating AKT pathway. It has been reported that AKT activation is involved in cell senescence $(18,19)$. To examine whether AKT activity is involved in TPL-induced HepG2 cell senescence, we detected the phosphorylated AKT level. Treatment of HepG2 cells with TPL significantly increased phosphorylated AKT level while phosphorylated AKT level reduced after treatment with TPL and MK2206 (AKT inhibitor) (Fig. 3A), indicating that TPL could enhance phosphorylated AKT level and activated the AKT pathway. Since AKT pathway was activated in response to TPL, the MK2206 was used to determine whether inactivation of AKT could relieve the acceleration of TPL on cellular senescence. As shown in Fig. 3B, the MK2206 relieved the acceleration of TPL on cellular senescence to a certain degree after treatment of HepG2 cells with TPL and MK2206 simultaneously. Taken together, these results showed that TPL activated the AKT pathway, contributing to acceleration of HepG2 cell senescence.

TPL enhances cellular senescence by inhibiting telomerase activity and hTERT expression. Telomere shortening and dysfunction are related to cellular senescence. Thus, we measured telomerase activity and hTERT expression after treating cells with $2.5 \mathrm{nM}$ TPL for 1 day and 3 days. As shown in Fig. 4A and B, TPL inhibited telomerase activity and hTERT expression in a time-dependent manner. Since hTERT expression was inhibited by TPL, the overexpression of hTERT was used to determine whether hTERT overexpression could reverse the inhibition of TPL on telomerase activity and hTERT expression. As shown in Fig. 4C and D, hTERT overexpression reversed the inhibition of TPL on telomerase activity and hTERT expression. Interestingly, we also found that hTERT overexpression could relieve the promotion of TPL on p53/p21 pathway (Fig. 4E) and cellular senescence (Fig. 4F). Taken together, these results indicated that TPL accelerates HepG2 cell senescence by negatively regulating hTERT signaling pathway.

TPL inhibits tumor growth by regulating hTERT pathway in vivo. A xenograft model was built to determine the effect of TPL on tumor growth in vivo. Compared with control group, tumor volume and weight reduced significantly in the TPL 
A

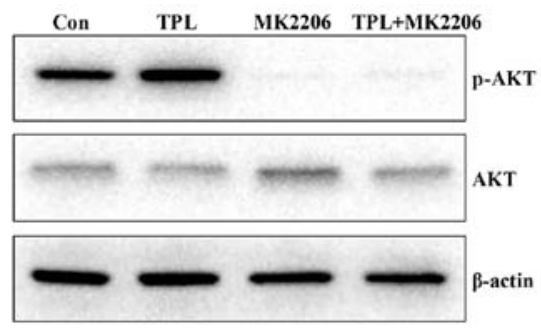

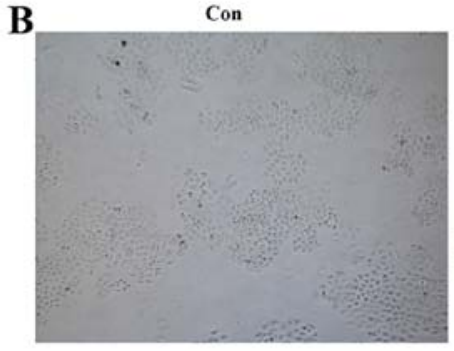

TPL

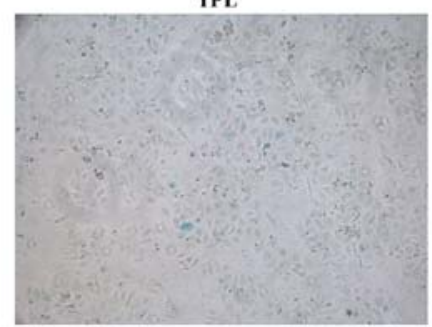

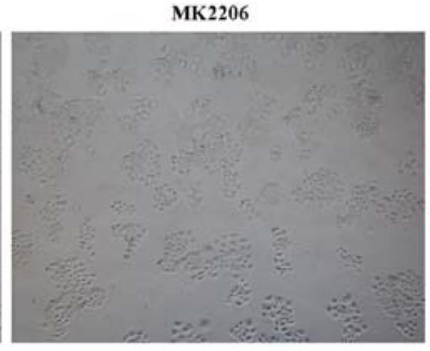

TPL+MK2206

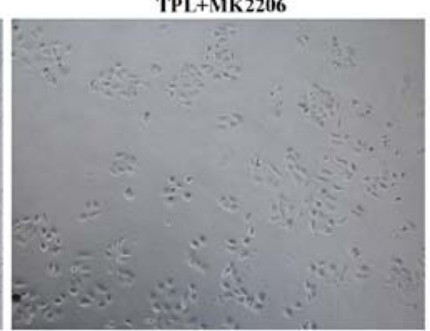

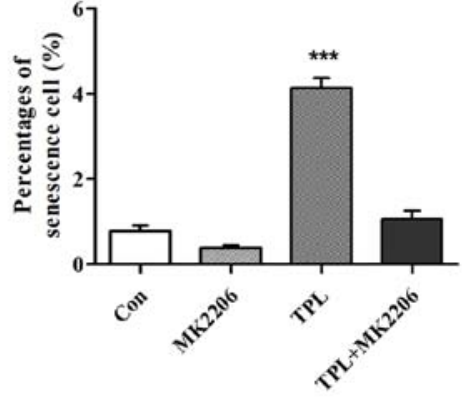

Figure 3. TPL accelerates cellular senescence by regulating the AKT pathway. (A) Western blot analysis shows regulation of TPL and MK2206 (AKT inhibitor) on p-AKT and AKT expression. $\beta$-actin was used as internal control. (B) Senescence-associated $\beta$-gal staining of HepG2 cells treated with TPL, MK2206, TPL+MK2206, and DMSO, respectively (x100). Data are presented as the mean \pm SD of three independent experiments. ${ }^{* * *} \mathrm{P}<0.001$.

group (Fig. 5A). Ki67 staining also demonstrated inhibition of TPL on liver cancer cell proliferation (Fig. 5B). We further studied the mechanism of TPL on tumor growth in vivo and found that TPL could inhibit hTERT expression and telomerase activity (Fig. 5C), moreover, TPL could also increase p53 and p21 expression (Fig. 5D). Taken together, these results showed that TPL downregulates the hTERT pathway, contributing to inhibition of tumor growth.

\section{Discussion}

TPL has been shown to decrease cell proliferation and induce apoptosis and cellular senescence in lung cancer (20). In this study, we found that TPL could inhibit HepG2 cell proliferation, accelerate cellular senescence and cell apoptosis, and arrest cells at $\mathrm{G} 0 / \mathrm{G} 1$ phase by regulating the $\mathrm{p} 53 / \mathrm{p} 21$ pathway. Cellular senescence, as a state of irreversible cell cycle arrest, can be induced by multiple pathways (21). AKT, a serine/threonine protein kinase, has a key role in regulation of cell survival, metabolism and protein synthesis (22). Increasing evidence indicates that active AKT signaling pathway can also induce cellular senescence $(18,23-25)$. However, the effect of AKT on cellular senescence in HepG2 cells is still unclear. We found that TPL could promote phosphorylated AKT level and activate AKT pathway, contributing to acceleration of HepG2 cell senescence. Furthermore, it was reported that berberine induced AKT activation and inhibited HepG2 cell survival (26), probably due to mTOR-dependent feedback pathways (27), which were consistent with our results. Taken together, these findings suggested that TPL plays an important role in acceleration of $\mathrm{HepG} 2$ cell senescence by activating the AKT pathway.

As a special type of RNA nuclear protease, telomerase maintains the telomere function and is involved in cell senescence and carcinogenesis. High telomerase activity has been found in malignant tumors while low telomerase activity is found in majority of normal tissues and benign tumors (28). As a catalytic subunit of telomerase, hTERT is the most important regulator of telomerase activity and telomere length, which is overexpressed in $>90 \%$ of tumor cells and promotes tumor cell proliferation (29). Therefore, suppression of telomerase activity and hTERT expression is one of the promising strategies in anticancer therapy (30). In the present study, we found that TPL treatment significantly inhibited telomerase activity, hTERT expression and promoted cellular senescence in HepG2 cells while hTERT overexpression reversed the effect of TPL on telomerase activity, hTERT expression and cellular senescence.

p53 plays an antitumor role and is closely associated with differentiation, DNA repair, apoptosis and cell cycle progression by modulating transcription of many genes (31). There are two p53 binding motifs at -1877 and -1240 related to the start of transcription in hTERT genes. Overexpression of p53 or p21 inhibits the hTERT promoter $(32,33)$, while silencing of hTERT in HEK 293 cells could promote p53 and p21 transcription and repress cell proliferation (31), suggesting that hTERT may be drawn into a feedback loop system. Interestingly, we also found that hTERT overexpression could 

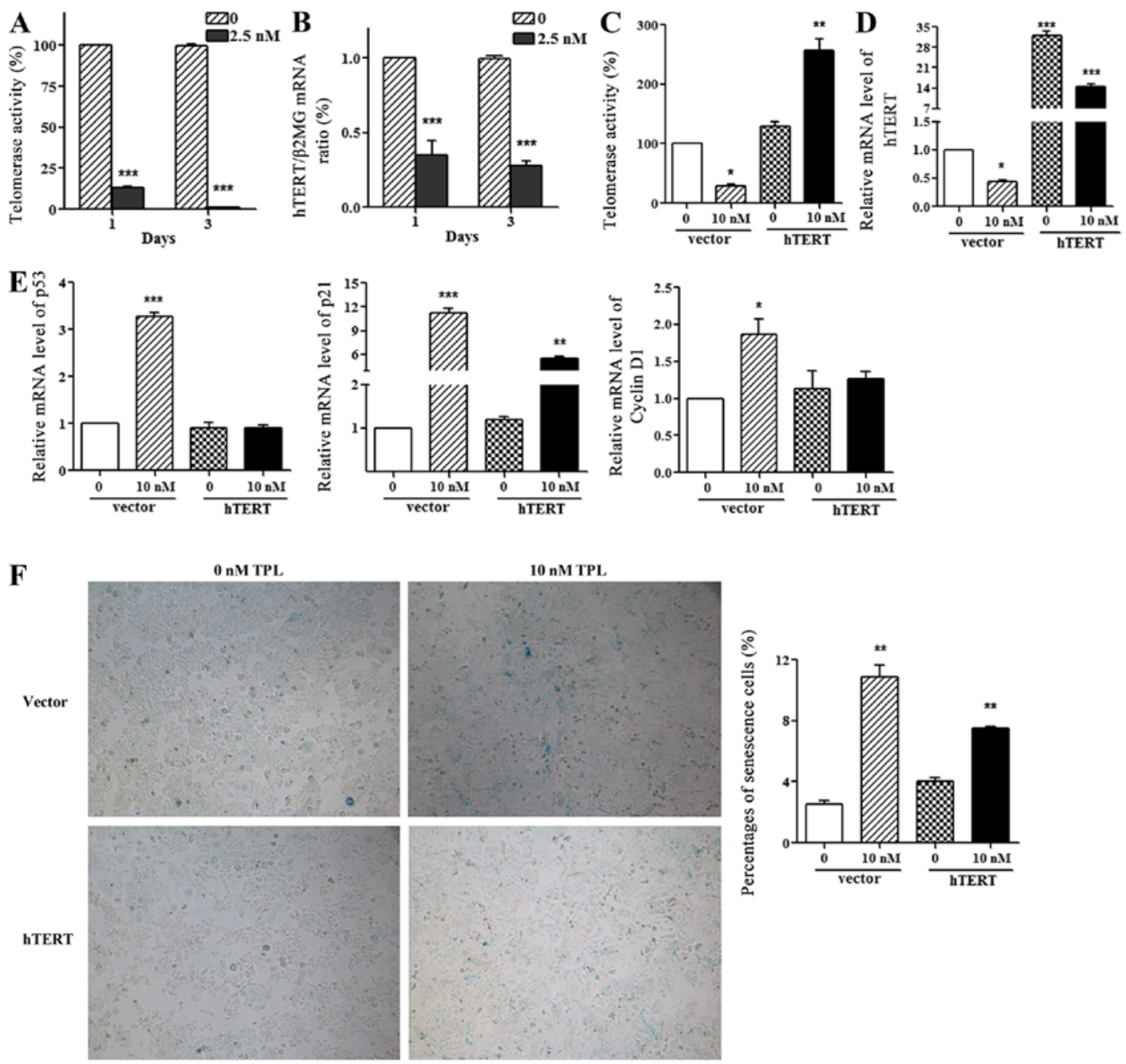

Figure 4. TPL accelerates cellular senescence by inhibiting telomerase activity and hTERT expression. (A) Telomerase activity in HepG2 cells treated with TPL. (B) RT-PCR analysis shows inhibition of TPL on hTERT mRNA expression. (C) Telomerase activity in HepG2 cells following TPL and overexpression of hTERT treatment. (D) hTERT mRNA expression in HepG2 was measured by RT-PCR analysis following TPL and overexpression of hTERT treatment. (E) p53, p21, cyclin D1 mRNA expression were determined by RT-PCR analysis following TPL and overexpression of hTERT treatment. $\beta$-actin was used as internal control. (F) Senescence-associated $\beta$-gal staining of HepG2 cells following TPL and overexpression of hTERT treatment (x100). Data are presented as the mean $\pm \mathrm{SD}$ of three independent experiments. ${ }^{*} \mathrm{P}<0.05,{ }^{* *} \mathrm{P}<0.01,{ }^{* * * *} \mathrm{P}<0.001$.

$\mathbf{A}$

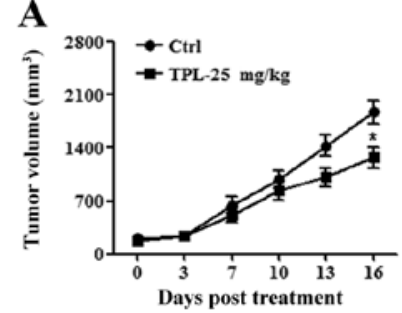

C

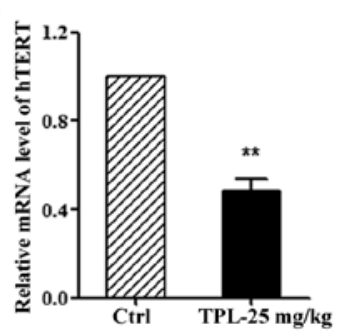

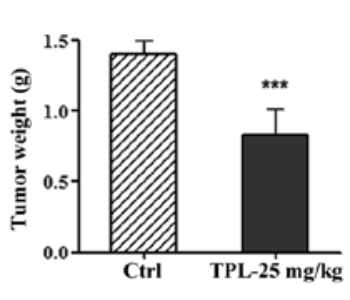

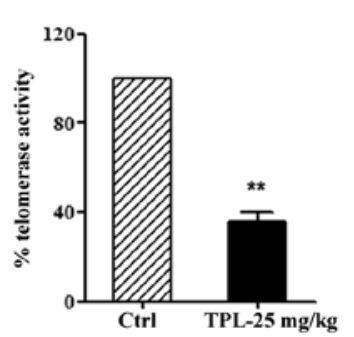

B

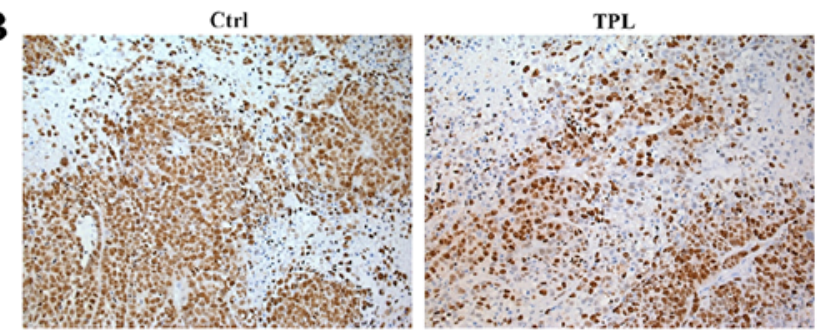

D
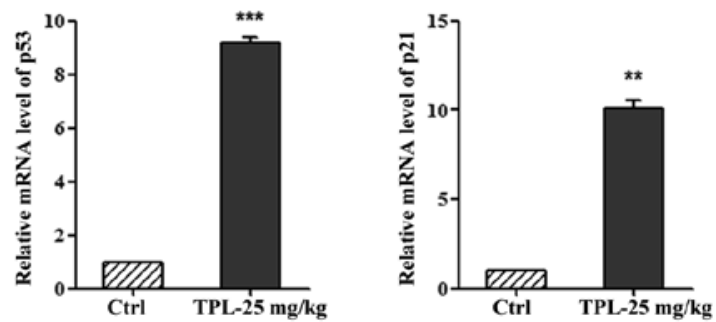

Figure 5. Effect of TPL on tumor growth in vivo. (A) Tumor volume and weight were evaluated in control group and TPL group. (B) Ki67 staining. (C) hTERT mRNA expression and telomerase activity in tumor tissues following TPL treatment. (D) RT-PCR analysis shows effect of TPL on p53, p21 mRNA expression in vivo. $\beta$-actin was used as internal control. ${ }^{* *} \mathrm{P}<0.01,{ }^{* * *} \mathrm{P}<0.001$. 
relieve the promotion of TPL on p53/p21 pathway. In addition, we demonstrated the effect and mechanism of TPL on tumor growth in vivo, and found that TPL inhibited tumor growth by negatively regulating the hTERT pathway.

In conclusion, we demonstrated that TPL inhibited tumor cell proliferation and growth in vitro and in vivo, induced cellular senescence and cell apoptosis, and arrested cells at G0/ G1 phase. We also demonstrated that TPL accelerated HepG2 cell senescence through AKT activation. Besides, TPL could also enhance cellular senescence by inhibiting telomerase activity and hTERT expression. These findings suggest that TPL accelerated HepG2 cell senescence by regulating AKT pathway and blocking hTERT pathway which resulted in inhibition of tumor growth, providing a promising strategy for cancer treatment and drug development.

\section{Acknowledgements}

This work was supported by the National Natural Science Foundation of China (no. 81001327).

\section{References}

1. Torre LA, Bray F, Siegel RL, Ferlay J, Lortet-Tieulent J and Jemal A: Global cancer statistics, 2012. CA Cancer J Clin 65: 87-108, 2015

2. Hayflick L and Moorhead PS: The serial cultivation of human diploid cell strains. Exp Cell Res 25: 585-621, 1961.

3. Collado M and Serrano M: Senescence in tumours: Evidence from mice and humans. Nat Rev Cancer 10: 51-57, 2010.

4. Braig M, Lee S, Loddenkemper C, Rudolph C, Peters AH, Schlegelberger B, Stein H, Dörken B, Jenuwein T and Schmitt CA: Oncogene-induced senescence as an initial barrier in lymphoma development. Nature 436: 660-665, 2005.

5. Bartkova J, Rezaei N, Liontos M, Karakaidos P, Kletsas D, Issaeva N, Vassiliou LV, Kolettas E, Niforou K, Zoumpourlis VC, et al: Oncogene-induced senescence is part of the tumorigenesis barrier imposed by DNA damage checkpoints. Nature 444: 633-637, 2006.

6. Rufini A, Tucci P, Celardo I and Melino G: Senescence and aging: The critical roles of p53. Oncogene 32: 5129-5143, 2013.

7. Provinciali M, Cardelli M, Marchegiani F and Pierpaoli E: Impact of cellular senescence in aging and cancer. Curr Pharm Des 19: 1699-1709, 2013.

8. Nardella C, Clohessy JG, Alimonti A and Pandolfi PP: Pro-senescence therapy for cancer treatment. Nat Rev Cancer 11: 503-511, 2011.

9. Acosta JC and Gil J: Senescence: A new weapon for cancer therapy. Trends Cell Biol 22: 211-219, 2012.

10. Kupchan SM, Court WA, Dailey RG Jr, Gilmore CJ and Bryan RF: Triptolide and tripdiolide, novel antileukemic diterpenoid triepoxides from Tripterygium wilfordii. J Am Chem Soc 94: 7194-7195, 1972.

11. Sun L, Li H, Huang X, Wang T, Zhang S, Yang J, Huang S, Mei H, Jiang $Z$ and Zhang L: Triptolide alters barrier function in renal proximal tubular cells in rats. Toxicol Lett 223: 96-102, 2013.

12. Reno TA, Kim JY and Raz DJ: Triptolide inhibits lung cancer cell migration, invasion, and metastasis. Ann Thorac Surg 100: 1817-1824; discussion 1824-1815, 2015.

13. Jiang XH, Wong BC, Lin MC, Zhu GH, Kung HF, Jiang SH, Yang D and Lam SK: Functional p53 is required for triptolideinduced apoptosis and AP-1 and nuclear factor-kappaB activation in gastric cancer cells. Oncogene 20: 8009-8018, 2001.

14. Li C, Xing G, Maeda K, Wu C, Gong L, Sugiyama Y, Qi X, Ren J and Wang G: The role of breast cancer resistance protein (Bcrp/Abcg2) in triptolide-induced testis toxicity. Toxicol Res 4: 1260-1268, 2015.
15. Yang S, Chen J, Guo Z, Xu XM, Wang L, Pei XF, Yang J, Underhill CB and Zhang L: Triptolide inhibits the growth and metastasis of solid tumors. Mol Cancer Ther 2: 65-72, 2003.

16. Wang Z, Jin H, Xu R, Mei Q and Fan D: Triptolide downregulates Racl and the JAK/STAT3 pathway and inhibits colitis-related colon cancer progression. Exp Mol Med 41: 717-727, 2009.

17. Phillips PA, Dudeja V, McCarroll JA, Borja-Cacho D, Dawra RK, Grizzle WE, Vickers SM and Saluja AK: Triptolide induces pancreatic cancer cell death via inhibition of heat shock protein 70. Cancer Res 67: 9407-9416, 2007.

18. Astle MV, Hannan KM, Ng PY, Lee RS, George AJ, Hsu AK, Haupt Y, Hannan RD and Pearson RB: AKT induces senescence in human cells via mTORC1 and p53 in the absence of DNA damage: Implications for targeting mTOR during malignancy. Oncogene 31: 1949-1962, 2012.

19. Sin S, Kim SY and Kim SS: Chronic treatment with ginsenoside $\mathrm{Rg} 3$ induces Akt-dependent senescence in human glioma cells. Int J Oncol 41: 1669-1674, 2012.

20. Reno TA, Tong SW, Wu J, Fidler JM, Nelson R, Kim JY and Raz DJ: The triptolide derivative MRx102 inhibits Wnt pathway activation and has potent anti-tumor effects in lung cancer. BMC Cancer 16: 439, 2016.

21. Collado M, Blasco MA and Serrano M: Cellular senescence in cancer and aging. Cell 130: 223-233, 2007.

22. Dimitrova V and Arcaro A: Targeting the PI3K/AKT/mTOR signaling pathway in medulloblastoma. Curr Mol Med 15: 82-93, 2015.

23. Park JH, Kim JJ and Bae YS: Involvement of PI3K-AKT-mTOR pathway in protein kinase CKII inhibition-mediated senescence in human colon cancer cells. Biochem Biophys Res Commun 433: 420-425, 2013.

24. Xu Y, Li N, Xiang R and Sun P: Emerging roles of the p38 MAPK and PI3K/AKT/mTOR pathways in oncogene-induced senescence. Trends Biochem Sci 39: 268-276, 2014.

25. Binet R, Ythier D, Robles AI, Collado M, Larrieu D, Fonti C, Brambilla E, Brambilla C, Serrano M, Harris CC, et al: WNT16B is a new marker of cellular senescence that regulates p53 activity and the phosphoinositide 3-kinase/AKT pathway. Cancer Res 69: 9183-9191, 2009.

26. Yu R, Zhang ZQ, Wang B, Jiang HX, Cheng L and Shen LM: Berberine-induced apoptotic and autophagic death of HepG2 cells requires AMPK activation. Cancer Cell Int 14: 49, 2014.

27. Zhang HH, Lipovsky AI, Dibble CC, Sahin M and Manning BD: S6K1 regulates GSK3 under conditions of mTOR-dependent feedback inhibition of Akt. Mol Cell 24: 185-197, 2006.

28. Kim NW, Piatyszek MA, Prowse KR, Harley CB, West MD, Ho PL, Coviello GM, Wright WE, Weinrich SL and Shay JW: Specific association of human telomerase activity with immortal cells and cancer. Science 266: 2011-2015, 1994.

29. Ponnala S, Chetty C, Veeravalli KK, Dinh DH, Klopfenstein JD and Rao JS: MMP-9 silencing regulates hTERT expression via $\beta 1$ integrin-mediated FAK signaling and induces senescence in glioma xenograft cells. Cell Signal 23: 2065-2075, 2011.

30. Noureini SK and Wink M: Antiproliferative effect of the isoquinoline alkaloid papaverine in hepatocarcinoma HepG-2 cells - inhibition of telomerase and induction of senescence. Molecules 19: 11846-11859, 2014.

31. Lai SR, Cunningham AP, Huynh VQ, Andrews LG and Tollefsbol TO: Evidence of extra-telomeric effects of hTERT and its regulation involving a feedback loop. Exp Cell Res 313: 322-330, 2007.

32. Kanaya T, Kyo S, Hamada K, Takakura M, Kitagawa Y, Harada H and Inoue M: Adenoviral expression of p53 represses telomerase activity through down-regulation of human telomerase reverse transcriptase transcription. Clin Cancer Res 6: 1239-1247, 2000.

33. Harada K, Kurisu K, Sadatomo T, Tahara H, Tahara E, Ide T and Tahara E: Growth inhibition of human glioma cells by transfection-induced P21 and its effects on telomerase activity. J Neurooncol 47: 39-46, 2000. 